\title{
Resíduos Sólidos em Santa Cruz da Venerada-PE: Descarte, Movimentação e Destino
}

\author{
Maria Auxiliadora da Conceição Benício ${ }^{1}$; Maria José da Conceição Benícioº ; \\ Livia Suilan Rosa Caffé $e^{3}$ Hesler Piedade Caffé Filho ${ }^{4}$
}

\begin{abstract}
Resumo: Este estudo trará contribuição não só para a atuação governamental no tange a gestão dos resíduos sólidos, como também com o intuito de colaborar com a ação pública em direção à conscientização para com a população. A pesquisa foi desenvolvida com o objetivo de analisar como é feito o descarte e gestão dos resíduos sólidos. O método escolhido foi a pesquisa descritiva, pesquisa documental, observação com registro de fotos, pesquisa bibliográfica e entrevista. O referencial teórico trouxe conteúdo de gestão pública e questões relacionadas ao gerenciamento dos resíduos sólidos. Os resultados apresentaram os registros fotográficos da situação de descarte, movimentação e coleta dos resíduos e a entrevista realizada com agentes públicos mostram um resumo sobre o dia a dia e a base de tomada de decisão desses agentes.
\end{abstract}

Palavras chaves: Gestão Pública, resíduos sólidos.

\section{Solid Waste in Santa Cruz da Venerada-PE: Disposal, Movement and Destination}

\begin{abstract}
This study will contribute not only to the governmental action in the area of solid waste management, but also to collaborate with public action towards raising awareness of the population. The research was developed with the objective of analyzing how the disposal and management of solid waste is done. The method chosen was the descriptive research, documentary research, observation with photo registration, bibliographic research and interview. The theoretical framework has brought public management content and issues related to solid waste management. The results presented the photographic records of the disposal situation, handling and collection of the waste and the interview with public agents show a summary about the day to day and the base of decision making of these agents.
\end{abstract}

Keywords: Public management, solid waste.

\section{Introdução}

O que se pode ou deve fazer com tanto lixo produzido no mundo por dia? E que fazer com os animais e plantas quando morrem? Para onde vão as folhas que caem das arvores? Passam pelo processo de reciclagem da natureza. Todas as plantas e animais mortos

\footnotetext{
${ }^{1}$ Graduanda em administração Pública pela Universidade Federal do Vale do São Francisco, auxiliadorabenicio@yahoo.com.br;

${ }^{2}$ Graduanda em administração Pública pela Universidade Federal do Vale do São Francisco, mariajose.benicio@yahoo.com.br;

${ }^{3}$ Graduada em Pedagogia pela UNEB - Universidade Estadual da Bahia Campus Juazeiro. Professora do Ensino Fundamental I - Secretaria Municipal de Educação de Juazeiro BA. Estudante do Curso de Especialização em Gestão Empresarial da FASJ. E-mail: liviasuil@bol.com.br;

${ }^{4}$ Mestre em Gestão de Políticas Públicas - UFRB - Universidade do Recôncavo Baiano. Administrador na UNIVASF - Universidade Federal do Vale do São Francisco. Professor da Pós Graduação em Gestão Pública - UNIVASF. Professor de Pós Graduação em Gestão Estratégica - FASJ - Faculdade São Francisco de Juazeiro. E-mail: hesler.caffe@ univasf.edu.br.
} 
apodrecem e se decompõe, são destruídos por larvas, minhocas, bactérias e fungos e os elementos químicos e nutrientes eles contem voltam a terra. Podem ficar no solo nos mares ou rios e serão usados novamente para plantas e animais. É um processo natural de reutilização de materiais. E um interminável ciclo de morte de composição, nova vida e crescimento. Um bom exemplo desse ciclo e o que acontece nos jardins quando folhas, frutos e plantas mortas caem no chão, decompõe-se e formam os humos, valioso por melhorar a estrutura e a textura do solo, assim enriquecido, o solo possibilita o aparecimento de novos seres vivos. A importância da composição na natureza, é muito eficiente no tratamento do lixo na realidade, não há propriamente lixo, pois ele é novamente usado e se transforma em substancia aproveitáveis.

Quando o homem explora os recursos da terra e não reutiliza, se polui com descarte desses produtos. A poluição impede e que os ciclos se reutilizem apropriadamente. Além disso, ele é repugnante e muitas vezes perigoso pois, ambientes poluídos, são nocivos para a saúde ameaçando o bem estar de nosso planeta e nossas próprias vidas. Se o lixo doméstico não for retirado de nossas casas, haverá logo acumulo de coisas podres que atrairão insetos e ratos. Embora esses animais ajudem a decompor o lixo, e podem também causar doenças que são contagiosas ao ser humano.

Ainda é bastante inquietante a questão do destino que toma os resíduos sólidos produzidos pela população brasileira. É sabido: Segundo a Norma Brasileira NBR 10004 de 2004 - Resíduos Sólidos são aqueles resíduos nos estados sólido e semi-sólido, que resultam de atividades da comunidade de origem industrial, doméstica, hospitalar, comercial, agrícola, de serviços e de varrição. Ficam incluídos nesta definição os lodos provenientes de sistemas de tratamento de água, bem como determinados líquidos cujas particularidades tornem inviável o seu lançamento na rede pública de esgotos ou corpos de água, ou exijam para isso soluções técnicas e economicamente inviáveis em face à melhor tecnologia disponível.

Este estudo é de grande importância pois trará grande contribuição não só para a atuação governamental no tange a gestão dos resíduos sólidos, como também com o intuito de colaborar com a prática de conscientização e reciclagem junto à população. Logo, essa pesquisa se desenvolveu no ambiente de um município, na qual foi realizada uma pesquisa afim de compreender melhor a origem e o destino final do lixo. Diante de todo o exposto fica a pergunta: como é feita a gestão dos resíduos sólidos da cidade de Santa Cruz da Venerada- 
PE?

Logo, o objetivo geral desse trabalho é analisar de que forma é feita a gestão dos resíduos sólidos da cidade de Santa Cruz da Venerada. Os objetivos específicos são: 1 Verificar a existência de descarte de lixo nas ruas; 2 - Saber como é feita a movimentação desses resíduos para local específico e 3 - conhecer as práticas públicas de destinação/reuso desses materiais;

Para isso, foi realizada uma pesquisa descritiva (MINAYO, 2000), a fim de conhecer os descartes de resíduos sólidos nas vias ruas, praças e locais públicos, bem como conhecer o processo de movimentação desses resíduos até local distante das moradias. Como coleta de dados a observação passiva e registro de fotografias. Na necessidade de conhecer as práticas públicas, foi necessária uma pesquisa documental (FONSECA, 2002), - considerando a possibilidade de políticas públicas ou decisões oficiais sobre o tema - o que pôde ser obtido também através de uma entrevista com agentes públicos relacionados ao processo. Ainda, será realizada uma pesquisa bibliográfica (GIL, 2002) para saber os tipos de poluição - o que e apresenta como base teórica para a pesquisa.

\section{Gestão Pública}

Quando se fala em gestão, a tendência é associar a empresa privada, contudo vale lembrar que, também no setor publico, a gestão deve estar presente como ferramenta para a administração, visando a melhoria a condições do trabalhador e dos serviços e produtos ofertados. Podemos observar no Brasil que a Administração do setor publico também recebe influencia em função das mudanças ocorridas nas praticas de gerenciamento.

Segundo Harmon e Mayer (1999), na administração publica estão todos aqueles que atuam em nome do povo em nome da sociedade, que delega de forma legal cujas ações tem consequências para os indivíduos e grupos sociais já para Tenório e Saraiva (2006) a gestão pública independentemente da organização que a pratique, deve estar orientada para o beneficio da comunidade e não dos compadres.

No Brasil segundo a Constituição Federal a Administração Pública se divide emdireta e indireta (Artigo 37, Caput, Constituição Federal de 1988). Pode ainda ser uma 
administração direta e centralizado o indireta descentralizada como são os casos das autarquias, empresas públicas, sociedades econômicas mista e fundações públicas. A Constituição Federal de 1988, também estabelece o comportamento dos gestores, em conformidade com os princípios constitucionais da administração pública (Art. 37, CF), a saber principio da legalidade, da impessoalidade, da moralidade, da publicidade, da eficiência.

Para Stelmach (2008), a administração pública é definida através de duas perspectiva: objetivamente, como uma atividade concreta e imediata onde o estado se desenvolve para assegurar os interesse coletivos e, subjetivamente como um conjunto de órgãos e de pessoas jurídicas aos quais a lei atribui o exercício da função da administrativa do estado. Ainda na visão de Stelmanch (2008), em relação ao aspecto operacional, a administração pública e o desempenho constante e sistemático, legal e técnico dos serviços próprio do estado, em beneficio da coletividade. Ela pode direta quando composta pelas suas entidades estatais (União, estados, municípios e Distrito Federal), que não personalidade jurídica própria ou indireta, quando composta por entidades, autarquias, fundacionais e para estatais.

É possível dizer que a administração publica - com relação aos instrumentos de governo, é uma gestão com os mesmos interesses da coletividade subjetivamente. A administração pública acaba sendo um conjunto de órgãos a serviços do estado agindo em concreto para satisfação de seus fins de conservação, de bem estar individual dos cidadãos e de progresso social. (MEIRELES, 2000).

Atualmente o gestor público tem o papel de integrar sua equipe, exigindo eficiência e eficácia nas prestações de serviços reunindo novos valores a administração publica em prol de serviços públicos de qualidade. Essa visão atual de serviços de qualidade, no entanto, ocorreu tão facilmente na administração publica patrimonialista (anterior a revolução de 30): administração política burocrática criação de departamento de administração do serviços públicos (DASP em 1983) administração publica gerencial com enfoque no cidadão, nos resultados e na descentralização dos serviços. Para Bresser Pereira (1966), o estado precisou ser reinventado e reformulado a partir da própria crise, sendo necessário redefinir tarefas e funções. 


\title{
Políticas Públicas de Coleta de Lixo
}

Com o aumento populacional e consequentemente aumento da produção de lixo ou resíduos sólidos por conta do cotidiano das pessoas e sociedade, faz-se necessário que o poder público pense estratégias para administrar esses resíduos evitando assim questões de saúde pública, estética e bem estar social.

\begin{abstract}
Nos dias atuais, com a maioria das pessoas vivendo nas cidades e com o avanço mundial da indústria provocando mudanças nos hábitos de consumo da população, vem-se gerando um lixo diferente em quantidade e diversidade. Até mesmo nas zonas rurais encontram-se frascos e sacos plásticos acumulando-se devido formas inadequadas de eliminação. (IPT/CEMPRE, 1995).
\end{abstract}

A modernidade, globalização, a questão da qualidade de vida e possibilidades de consumo doméstico e comercial, fez com que as pessoas produzissem uma certa quantidade de lixo e automaticamente descartassem fora de suas casas - em ruas, vias, ambientes urbanos. A questão da reciclagem ainda não é uma prática que acontece nos domicílios e ambientes empresariais.

As montanhas de lixo começaram a surgir com o desenvolvimento econômico, sobretudo a partir da II Guerra Mundial, período de prosperidade nunca visto na história da humanidade que provocou uma mudança radical nos padrões de produção e consumo, bem como nas mentalidades e atitudes das pessoas. (PEREIRA, 2004, p. $30)$.

O gerenciamento do lixo ou resíduos sólidos, encontra base em ações e atitudes que precisam estar alinhadas com o tratamento, acondicionamento, destino, que por sua vez está alinhado à uma cultura regional e local. O objetivo disso tudo é a diminuição do impacto ambiental, econômico e social do acumulo de resíduos.

É possível que os cidadãos convivam com a grande maioria do lixo que eles mesmos produzem - considerando que é de senso comum que a maioria dos lixos produzidos na área urbana têm como destino os lixões e aterros sanitários.

Para a maioria dos administradores o lixo é encarado como um problema e uma preocupação meramente higiênica. Porém, o problema maior são as medidas paliativas e impactantes adotadas, como a de afastar dos olhos e das narinas esse 
incômodo e apresentar uma falsa solução à população. (FADINI; BARBOSA, 2001, p.10).

Para Vieira (2006), as leis e exercício da coisa pública precisa gerenciar as estratégicas com base nas dimensões urbanas a fim de estabelecer uma governabilidade, que atinja níveis de eficiência e eficácia no quesito do lixo. Para isso, faz-se necessário, além de ações públicas, a coperação dos demais atores sociais.

Para Vieira (2006), existem alguns passos para tratamento e destino final de resíduos sólidos. Lixões, aterros, incineração, são alguns deles:

No Brasil, a etapa da destinação final das diferentes tipologias de lixo compreende a disposição no solo, em lixão, aterro controlado ou aterro sanitário, a separação para reciclagem / compostagem e reutilização, tratamento por assepsia ou incineração, com aterramento total ou somente do rejeito da separação ou tratamento. (VIEIRA, 2006, p.59).

É perceptível quem nem toda a forma de destinação dos resíduos sólidos produzidos em nossas residências, nas industriais, nos hospitais dentre outros lugares são adequadas. Existem alguns passos para tratamento e destino final de resíduos sólidos. Um quadro adaptado de Siqueira e Semensato explica algumas delas.

\section{Quadro: Destino e Gestão dos Resíduos Sólidos}

\begin{tabular}{|c|c|}
\hline TIPOS DE DESTINO & DESCRIÇÃO. \\
\hline LIXÃO & $\begin{array}{l}\text { São áreas distantes dos centros urbanos reservadas para o depósito de } \\
\text { lixo, encontram-se nas proximidades das periferias. Para Fadini e } \\
\text { Barbosa (2001), o grande problema é que os resíduos ficam expostos a } \\
\text { "céu aberto". Este processo é a pior forma de tratamento final pois causa } \\
\text { vários problemas ambientais, tais como poluição do solo, poluição dos } \\
\text { lençóis freáticos, poluição do ar, poluição visual e proliferação de insetos } \\
\text { e roedores. }\end{array}$ \\
\hline ATERROS SANITÁRIOS & $\begin{array}{l}\text { São espaços destinados ao depósito final do lixo, a área construída para } \\
\text { esta finalidade deve receber constante manutenção para manter a } \\
\text { qualidade do tratamento, o solo do local deve ser impermeabilizado e } \\
\text { deve conter um sistema adequado de escoamento do chorume }{ }^{5} \text { e dos } \\
\text { gases. }\end{array}$ \\
\hline INCINERAÇÃO & $\begin{array}{l}\text { É um tipo de tratamento para resíduos classificados como perigosos, tais } \\
\text { como o lixo hospitalar. Os resíduos são queimados em altas temperaturas } \\
\text { de forma controlada. Este tipo de tratamento é muito caro e necessita de } \\
\text { manutenção constante para evitar o lançamento de gases poluentes na } \\
\text { atmosfera. }\end{array}$ \\
\hline
\end{tabular}

\footnotetext{
${ }^{5}$ Líquido de alto teor de matéria orgânica, pode apresentar metais pesados, é formado ela umidade presente nos resíduos durante a decomposição dos materiais descartados 


\begin{tabular}{|c|l|}
\hline COMPOSTAGEM & $\begin{array}{l}\text { Baseia-se na separação e no tratamento do lixo orgânico, visa obter um } \\
\text { composto que pode ser usado como adubo em atividades agrícolas e } \\
\text { também pode ser utilizado como complemento alimentar de animais. } \\
\text { Este tipo de tratamento deve ser implantado sobre técnicas adequadas } \\
\text { para evitar o odor e a proliferação de insetos e roedores. }\end{array}$ \\
\hline ENCAPSULAMENTO & $\begin{array}{l}\text { Que consiste em imobilizar os resíduos perigosos através do } \\
\text { envolvimento/revestimento com matéria de baixa impermeabilidade. }\end{array}$ \\
\hline SOLIDIFICAÇÃO & $\begin{array}{l}\text { É um tipo de processo que compacta o resíduo na forma de um material } \\
\text { sólido e restringe a migração de seus contaminantes }\end{array}$ \\
\hline BIODIGESTÃO & $\begin{array}{l}\text { É um tipo de tratamento para resíduos. É realizada através de um } \\
\text { biodigestor, uma câmara de fermentação, trata-se de um recipiente } \\
\text { fechado onde a biomassa sofre digestão por bactérias, produzindo dois } \\
\text { tipos de produtos, o biogás e o fertilizante. }\end{array}$ \\
\hline RECICLAGEM & $\begin{array}{l}\text { É um tipo de tratamento utilizado como meio de recuperar materiais } \\
\text { descartados nos lixos ou separados através da coleta seletiva, são úteis } \\
\text { para o processamento de componentes usados na produção de novos } \\
\text { produtos/objetos. }\end{array}$ \\
\hline
\end{tabular}

Fonte: Elaborado pelos autores, 2017.

É perceptível que os aterros que têm uma melhor estrutura para receber esses resíduos, como são os casos dos aterros controlados e dos aterros sanitários ainda são em um percentual bem pequeno em se tratando da quantidade de lixo que é produzida diariamente.

Esses aterros têm o solo preparado para receberem esse lixo, o que não acontece nos lixões a céu aberto. Os aterros sanitários também possuem sistema de drenagem para o chorume (liquido tóxico que resulta da decomposição do lixo), que é levado para tratamento, sendo depois devolvido ao meio ambiente sem risco de contaminação.

Os aterros sanitários são cobertos por solo e compactado com tratores, o que dificulta ação de insertos e outros vetores transmissores de doenças para a população. É importante ressaltar que a construção desses aterros está pautada, em normas da associação brasileira de normas técnicas (ABNT), e que existem poços de monitoramento da água abertos próximos a esses aterros para se avaliar a situação desta para que não haja possíveis contaminações.

Portanto, cabe ao poder público definir taxas, periodicidade, escolher modalidade, fazer coleta, transbordo, bem como sistematizar dados, além de processar e comercializar os resíduos sólidos urbanos recicláveis ou reutilizáveis. Essas e outras diretrizes estão previstas nas seguintes prerrogativas:

- Projeto de Lei do Senado no 354, de 1989 (no 203, de 1991, na Câmara dos Deputados)

- Lei Federal No 11.445, de 5 de janeiro de 2007

- Decreto Federal 5.940 de 25 de outubro de 2006. 
Vale ressaltar ainda que seja necessária uma fiscalização nesses destinos para que seja selecionado também o tipo de lixo que deposita nesses espaços, uma vez que se utilizado de forma desordenada, receberem lixos perigosos como, os nucleares e os hospitalares, podem acabar resultando, nos mesmos problemas dos lixões a céu aberto, com vazamento do chorume e de gases altamente poluentes.

\section{Resultados Encontrados}

O lixo jogado nas ruas é um problema de muitas cidades, causado por muitas pessoas esse tipo de atitude é indevido porem às vezes as pessoas ate sabem do tamanho do problema que estão apenas transferindo de um local para outro, é preciso ações públicas para controle desses resíduos.

A foto abaixo de uma das principais avenidas da Cidade de Santa Cruz-PE, mostra a falta de responsabilidade por parte da população, existem cestas nas ruas mais mesmo assim as ruas são muito sujas de lixos jogados após o caminhão de coleta passar.

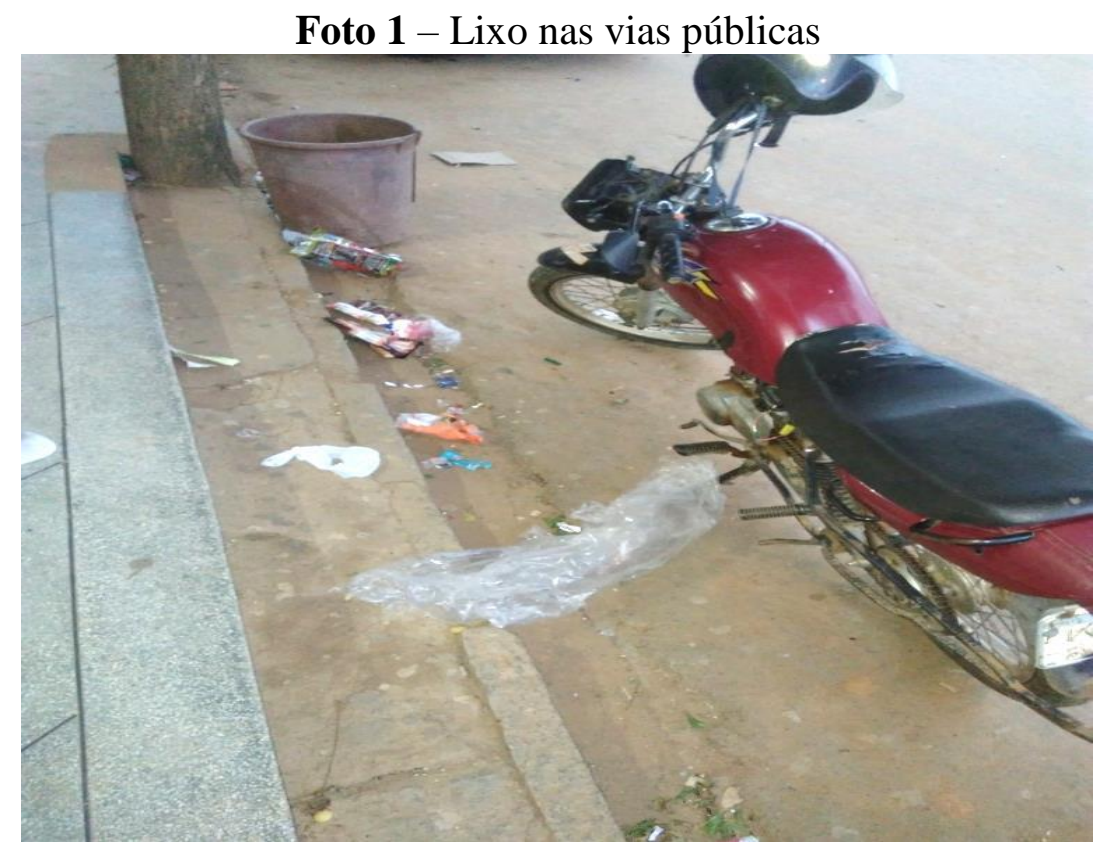

Fonte: Coletada pelos autores. 2017. 
O atual lixão de Santa Cruz é um problema de muitos anos, é a céu aberto onde é espaço de varias espécies de animais, o mesmo é preocupante pois o perigo só aumenta a cada dia, lixo de hospitais, animais mortos, poda de arvore, destroços de construção entre outros.

\section{Foto 2 - Lixão}

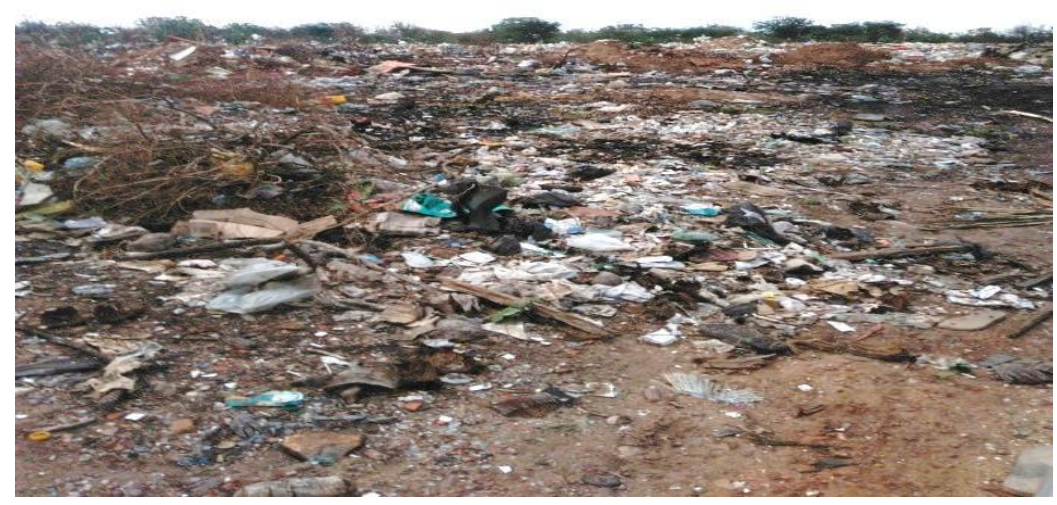

Fonte: Coletada pelos autores. 2017.

Existem cestas de lixo espalhadas pelas ruas para facilitar a coleta de lixo, o certo é jogar os lixos nas cestas mais nem sempre isso acontece, e outras vezes o vendo retira da cesta e volta para a rua. 
Id on Line Revista Multidisciplinar e de Psicoloqia

Id on Line Multidisciplinary and Psycology Journal

Foto 3 - Descarte de lixo na via pública

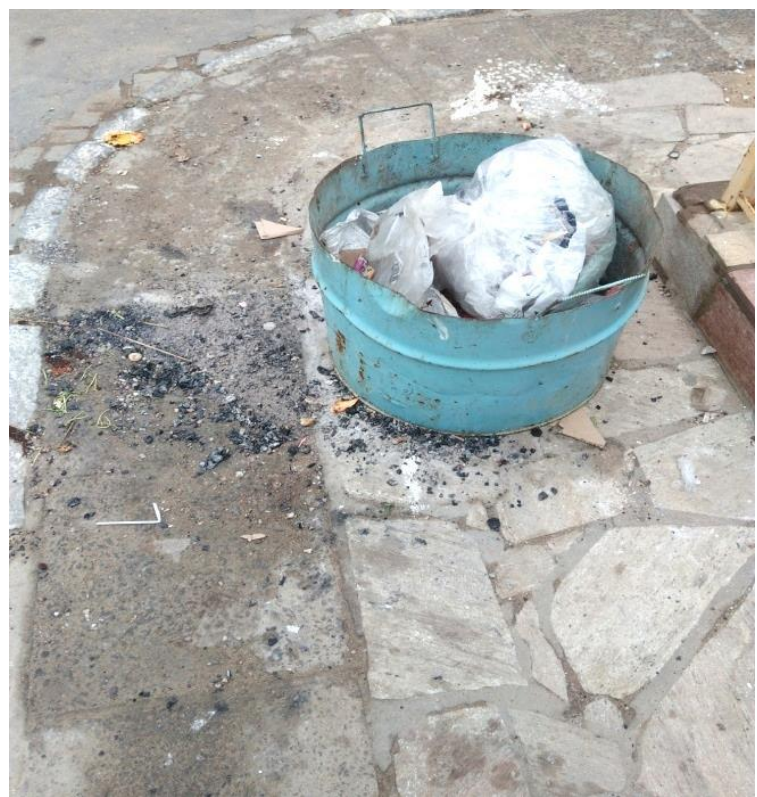

Fonte: Coletada pelos autores. 2017.

O lixo espalhado pela cidade ainda é um grande problema, há pessoas sem consciência que usa jogar lixo nos terrenos baldios no chão, nas praças quando estão passando por ali, às vezes para dificultar o trabalho do gari pois uma boa parte usa a expressão estão ganhando para isso.

Foto 4 - Lixo espalhado da praça Aureliano Alves de Souza

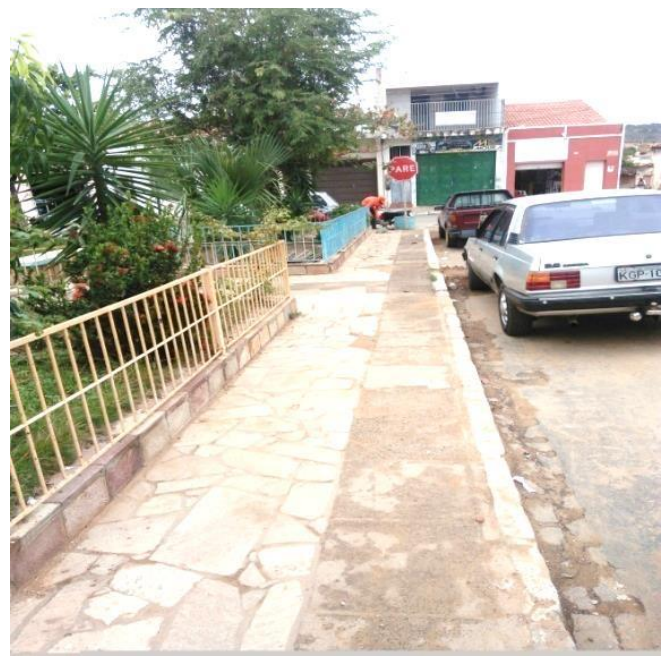

Fonte: Coletada pelos autores. 2017. 
Todos os dias um caminhão do tipo caçamba faz a coleta nas principais ruas e comércios, e nas demais ruas existe uma planilha onde em todas se passa pelo menos 2 vezes na semana, logo após é jogado no lixão principal.

\section{Foto 5 - Coleta de lixo}

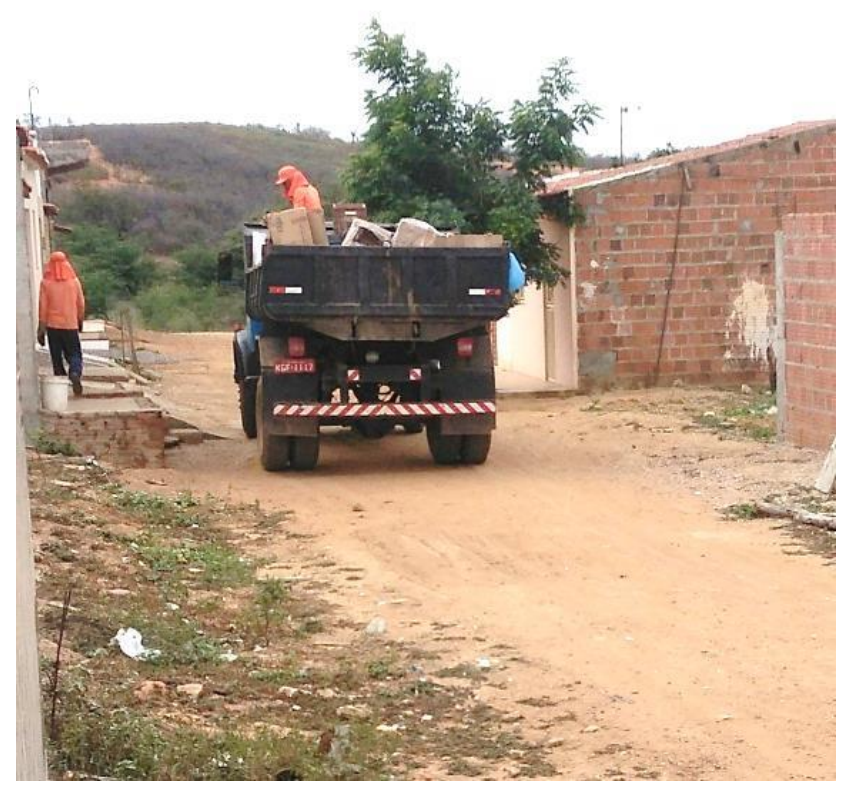

Fonte: Coletada pelos autores. 2017.

Perto do lixão principal existe esse ponto de reciclagem, são de papelões, alumínio, dentre outros produtos recicláveis. Os catadores corem um serio risco pois nenhum usa material apropriado para reciclagem, e também é coletado junto a todos os outros tipos, inclusive hospitalar. 


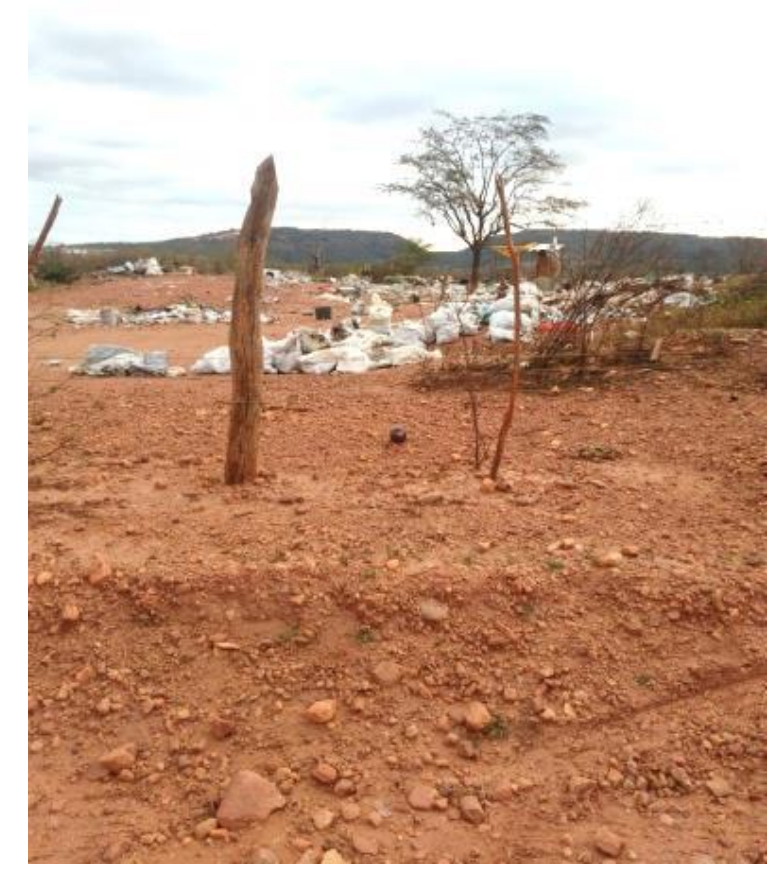

Fonte: Coletada pelos autores. 2017.

Em reunião com um represente gari do quadro, confirmando as informações ja citadas que é de conhecimento da população, eles todos os dias conforme planilha de divisórias de ruas e pessoas fazem a limpeza da cidade, logo após outros garis com carinho de mão pega o lixo, e o caminhão recolhe logo após, todo lixo é levado para o lixão já mostrado e despejado sem ser feito nenhum processo, ficando apenas a céu aberto e com a certeza de que nem o tempo conseguira acabar com aquele tão grande lixão.

Conforme dito pela equipe, já existe uma licitação aprovada por uma empresa responsável por criar um lixão adequado conforme a lei manda. Não tivemos acesso ao nome da empresa e nem ao certo quando ira começar o trabalho, o mesmo vai ser feito com o lixo hospitalar, uma empresa especializada vira buscar todos os lixos, também através de processo licitatório. Existe uma equipe de mais de 50 pessoas envolvidas na coleta do lixo, pois a uma equipe que vare outra que recolhe para as cestas, outra equipe que anda no caminhão que essa é a mesma que leva e despeja no lixão. Espera se que ate junho de 2018 esteja tudo conforme a lei, já que os primeiros passos foi dado. 


\section{Conclusão}

Partindo do resultado dessa pesquisa, fica mais evidente a preocupação que devemos ter com o destino dos resíduos que produzimos diariamente. Os esgotos e os lixões a céu aberto geram bastante preocupação quanto à saúde do ser humano que fica bastante vulnerável, os esgotos geralmente deságuam em rios e lagos que são utilizados como meio de consumo da população. Os lixões agridem diretamente o meio ambiente e também as pessoas, uma vez que além de poluir o solo e o ar, ainda torna-se depósitos de insetos como, moscas, baratas e até vetores como o Aeds Aegipthy, que é o transmissor da da febre amarela urbana.

Além dessa preocupação em relação aos lixões a céu aberto, existe outra não menos importante, que é a presença de pessoas nesses locais, a fim de encontrarem uma fonte de subsistência, catando papelão, separando revistas, latas, plásticos e outros objetos para reciclagem. Muitas vezes crianças e idosos estão nesses locais expostos a vários perigos, pois alem de insetos, estão presentes ali também objetos cortantes, objetos corrosivos, alimentos contaminados, entre outros.

A pesquisa apresentou dados relacionados ao descarte de resíduos sólidos através de fotografias coletadas nos diversos locais da cidade. Além disso, mostra também como acontece o transporte desses resíduos, que passam 2 vezes por semana em um caminhão aberto. Por fim, a entrevista mostrou informações da representação dos trabalhadores que fazem a coleta, aqui denominada 'gari', que por sua vez atende a uma planilha (desenvolvida pelo poder público), que organiza a coleta desses resíduos sólidos. A pesquisa mostrou também que existe uma licitação aprovada e o fruto dessa licitação é a criação de um lixão adequado, conforme determinações legais descritas naquele certame.

Logo, os objetivos foram alcançados pois, descreveu a realidade da situação encontrada na cidade de Santa Cruz da Venerada. O método foi suficiente para ilustrar o objetivo do trabalho e o referencial teórico, contendo tema da gestão pública e da gestão os resíduos sólidos, permitiu dar embasamento suficiente para entender do que se trata a pesquisa proposta. 


\section{Referências}

BRESSER PEREIRA, L.C. Da administração pública Burocrática à gerencial. Revista do Serviço Público, Trabalho apresentado ao seminário sobre Reforma do Estado na América Latina organizado pelo Ministério da Administração Federal e Reforma do Estado e patrocinado pelo Banco Interamericano de Desenvolvimento. 1996. Disponível em <http://www.bresserpereira.org.br/papers/1996/95.AdmPublicaBurocraticaAGerencial.pdf $>$. Acesso em 27 de junho de 2017.

FADINI, Pedro Sérgio; BARBOSA, Almerinda Antônia Fadini. Lixo: desafios e compromissos. Cadernos Temáticos de Química Nova na Escola. São Paulo: Edição especial, Maio 2001.

FONSECA, J. J. S. Metodologia da pesquisa científica. Fortaleza: UEC, 2002. Apostila.

GIL, A.C. como elaborar projetos de pesquisa. São Paulo: ATLAS 2002.

HARMON, M. M.; MAYER, R. T. Teoria de la organización para la administración pública. [Trad. nossa]. México: Colegio Nacional de Ciências Políticas y Administración Pública A. C./ Fondo de Cultura Económica, 1999.

IPT/CEMPRE. Lixo municipal: manual de gerenciamento integrado. Instituto de Pesquisas Tecnológicas. São Paulo: IPT 2163, 1995.

MEIRELLES, Hely Lopes. Direito Administrativo Brasileiro. 25. ed. São Paulo: Malheiros, 2000.

MINAYO, Maria Cecilia de Souza; DESLANDES, Suely Ferreira; CRUZ NETO, Otávio; GOMES, Romeu (Coord.). Pesquisa social: teoria, método e criatividade. 16. ed. Petrópolis: Vozes, 2000. 80 p.

PEREIRA, Maria de Fátima Rodrigues. A importância do Saneamento Ambiental e da Gestão Sustentável do Lixo em Regiões de Favelas - $O$ caso prático do Morro do Andaraí. Tese de mestrado. Rio de Janeiro, 2004.

SIQUEIRA, A.A. SEMENSATO, L.R. Resíduos Sólidos: Problemas E Desafios. Artigo sem ano de referencia. Disponível em <http://www.unifaj.edu.br/NetManager/documentos/Residuos_solidos.pdf $>$ Acesso em $01 \mathrm{de}$ julho de 2017.

STELMACH, Eder Renato. Administração Pública. 2008. Disponível em: $<$ http://www.administradores.com.br/artigos/economia-e-

financas/administracaopublica/26437/>. Acesso em: 27 de junho de 2017. 
Id on Line Revista Multidisciplinar e de Psicoloqia

Id on Line Multidisciplinary and Psycology Journal

VIEIRA, Elias Antônio. Lixo - Problemática Socioespacial e Gerenciamento Integrado: a experiência de Serra Azul. Tese de doutorado. São Paulo, 2006.

\section{Como citar este artigo (Formato ABNT):}

BENÍCIO, Maria Auxiliadora C.; BENÍCIO, Maria José C.; CAFFÉ, Lívia S.R.; CAFFÉ FILHO, Hesler P. Resíduos sólidos em santa Cruz da Venerada-PE: Descarte, Movimentação e Destino. Id on Line Revista Multidisciplinar e de Psicologia, Julho de 2017, vol.11, n.36, p 268-282. ISSN: 1981-1179.

Recebido: 19.06 .2017

Aceito: 06.07.2017 